\title{
A Rare Presentation of Granular Cell Tumor of Tongue- A Case Report
}

\author{
Dr. Surej Kumar LK ${ }^{\text {A }}$ Dr. Vinod Nair $S^{\text {B*}}$,Dr. Ranjana Ravindran ${ }^{\mathrm{C}}$ \\ ${ }^{a}$ Consultant Maxillofacial Surgeon, Kerala Institute of Medical Sciences (KIMS), \\ Trivandrum, India \\ ${ }^{b}$ Resident, Department of Oral and Maxillofacial Surgery, P.M.S Dental College, Vattapara, \\ Trivandrum, India \\ ${ }^{c}$ Intern, Department of Oral and Maxillofacial Surgery, P.M.S Dental College, Vattapara, \\ Trivandrum, India
}

\begin{abstract}
Introduction: Granular cell tumor is a soft tissue neoplasm that originates in the nervous system and arises at virtually any body site, but is mainly found in the skin, oral cavity or digestive tract. It is an uncommon benign hamartomatous lesion also known as Abrikossof tumor. This mesenchymal neoplasm apparently arises from neural or Schwann cell origin with benign and malignant forms.

Presentation Of A Case

A thirty year old male patient presented with a swelling on the dorsal surface of tongue, since one year with gradual increase in size. On examination, well defined nodular growth, firm in consistency, non pedunculated and surface of swelling was smooth. Clinically a differential diagnosis of fibroma or schwannoma was made.

Discussion: Although we have many differential diagnoses, our working diagnosis was schwannoma of tongue, so conventional treatment of excision was planned. Surprisingly histopathologic report was contradicting to clinical diagnosis.

Conclusion: Hence this is a unique case which appeared as an ambiguous swelling in relation to dorsal surface of tongue which was initially misdiagnosed as schwannoma and on histopathologic examination found to be a rare case of Granular Cell Tumor of Tongue.
\end{abstract}

\section{Introduction}

Granular cell tumor is an uncommon benign hamartomatous lesion also known as Abrikossof tumor. It was first described in 1926 as a tumor of the tongue, composed of granular cells from the striated muscles. Abrikossof named it as granular cell myoblastoma, because of the association of granular cell and skeletal muscles. Oral granular cell tumors are too uncommon to assess the incidence rate .It is twice as frequently seen in females than in males. The age range for occurrence of granular cell tumor is from second to eight decade, most commonly occurring in fourth and fifth decade.

\section{Case Presentation}

A thirty year old male patient presented with a swelling on the dorsal surface of tongue, since one year with gradual increase in size (Fig 1). On examination, well defined nodular growth, firm in consistency, non pedunculated and surface of swelling was smooth (Fig 2). Clinically a differential diagnosis of fibroma or schwannoma was made. To rule out the possibility of a vascular lesion, an ultrasound was taken but was suggestive of a vascular lesion. Considering ultrasound report, MRI and CT- Angio was taken to rule out vascular lesion. An excisional biopsy was planned and the entire lesion was excised in toto (Fig 3). Excised specimen was firm in consistency, brownish in color, $2 \times 1.5 \mathrm{cms}$ and oval in shape (Fig 4). Histopathological report was suggestive of a granular cell tumor contradicting to clinical diagnosis. $\mathrm{H}$ and $\mathrm{E}$ stained section revealed a parakeratinized stratified squamous epithelium with pseudoepitheliomatous hyperplasia and connective tissue enclosed shows tumor cells arranged in the form of nests (Fig 5 and 6). These neoplastic cells are polygonal in shape with abundant coarse eosinophilic granular cytoplasm and pale eccentric nuclei, some of which are vesicular. They exhibit mild hyperchromatism and pleomorphism(Fig 7). Postoperative period was uneventful and healing was satisfactory (Fig 8 and 9).

\section{Discussion}

Granular cell tumor (GCT), Abrikossoff's tumor (AT) or Myoblastoma (My) is a rather uncommon benign neoplasm which was first described in 1926 by Abrikossoff, ${ }^{1}$ who named it "myoblastenmyome". Abrikossof was the first person to identify a lesion on the tongue as granular cell myoblastoma, a term reflecting 
skeletal muscle origin. Since then, this tumor gained importance in the late 1970's. The apparent association between GCT and skeletal muscle, has led to it being known as granular cell myoblastoma and granulocellular rhabdomyoma. $^{2}$

The age range for occurrence of granular cell tumors is from the second to the eighth decade, most frequently in the fourth and fifth decades. Oral granular cell tumors are too uncommon to assess the incidence rate .It is twice more commonly seen in females than in males. Rare familial cases have been reported. From the literature review, it was found that no anatomical site is immune to the occurrence of GCT. A greater number of tumors tend to occur in the skin and subcutaneous tissues, compared to the occurrence of tongue being the most common site for GCT. GCTs have also been reported in sites such as skin, oesophagus, larynx, stomach, bile duct, and male and female reproductive tract. ${ }^{3}$

A lot of controversies have arised on the etiology of GCT .Originally, it was believed to arise from striated muscles, myoepithelium or fibroblasts and because of this uncertainty and it was referred to as granular cell myoblastoma. Histologic analysis of GCT shows it to be poorly circumscribed and composed of numerous strands and sheets of large polyhedral cells, 30-60 $\mu \mathrm{m}$ in diameter, with the distinct cellular membrane. Strips of connective tissue are observed to be separated from the surrounding areas by typically dense fibrous proliferative tissue with pseudoepitheliomatous overlying surface, which confuses GCT with squamous cell carcinoma. But recently, literatures have shown that the unique granular cells are predominantly of neural origin. This was possible only due to the advanced immunohistochemical techniques, which have localized a neuron-specific enolase and S-100 protein markers ${ }^{4}$.

Because of its indurative nature, often this tumor is confused with a malignant tumor. A meticulous way of biopsy/frozen section can often prevent a needless radical surgery. A common clinical feature associated with the lesion is the loss of gustatory papillae with or without atrophy of the mucosa. This specific clinical ulceration of the overlying mucosa may mimic a squamous cell carcinoma. This misdiagnosis may result in a more radical approach which is usually not necessary. In such instances, a biopsy is recommended. If incisional biopsy is performed, it should be deep enough so that underlying infiltrating granular cells are included. Clinically, it has been reported to occur as a single subcutaneous nodule, but multiple lesions have also been reported. ${ }^{5}$ The cases of multiple lesions account for about $5-25 \%$ of all cases of granular tumors. ${ }^{2}$ Studies have shown that persons presenting initially with a solitary GCT can later develop even multiple lesions. ${ }^{5}$ Differential diagnosis to be considered in cases of granular cell tumor are traumatic fibroma, neurofibroma, schwannoma, minor salivary gland tumors, lymphomas and congenital epulis on newly-born.

Numerous cell types have been proposed as the cells of origin, including histiocytes, fibroblasts, myoblasts, neural sheath cells, neuroendocrine cells, and undifferentiated mesenchymal cells. Although the histogenesis of the GCT has not been conclusively proven, immunohistochemical and ultrastructural studies support the origin of the lesion from Schwann cells. Immunocytochemical markers for S-100, neuron-specific enolase, myelin basic protein, are used to substantiate the neural origin. Positive staining for Luxol fast blue, a myelin stain provides supporting evidence of the neural origin for GCT. Chrysomali and colleagues assessed the cell proliferation activity and apoptosis in oral GCT and brought forth an opinion that there is activation of the apoptotic cascade in the GCs, but the persistence of the cells in the tissues could be attributed to the expression of Bcl-2 protein, a molecule that functions as a survival factor. ${ }^{7}$

Existence of squamous cell carcinomas and granular cell tumors is rare but has been documented. Although granular cell tumors are benign, clinically $10 \%$ have shown to have a malignant behaviour ${ }^{8}$ and $2 \%$ with distant metastasis. Some authors are of the suggestion that the distinction between benign and malignant types is fairly difficult because there is striking histological similarity between both varieties and a lack of reliable criteria to provide a prediction of development of a malignant behaviour. Surgical excision is the first line of treatment for all granular cell tumors, even for multifocal lesions. ${ }^{2}$ The lesion has to be excised with a safe margin since GCT has poorly defined borders. Radiation and chemotherapy is not a recommended treatment choice for GCT because of its benign nature. Mohs' micrographic surgery may be indicated in cases where tissue preservation is essential, such as in areas like oral cavity. ${ }^{9}$

Recurrence is uncommon and is, frequently, a result of incomplete excision of the original lesion. Very rarely, spontaneous regression has been reported in literature. After surgery, long-term follow-up should be started, because there is a risk of local or distant recurrence even several years after surgery. ${ }^{10}$

\section{Conclusion}

Hence this is a unique case which appeared as an ambiguous swelling in relation to dorsal surface of tongue which was initially misdiagnosed as schwannoma and on histopathologic examination found to be a rare case of Granular Cell Tumor of Tongue. 


\section{Legends}

Fig 1. Clinical presentation

Fig 2. Firm, non pedunculated swelling on dorsum of tongue

Fig 3. Excision of lesion in toto

Fig 4. Excised specimen

Fig 5. Photomicrograph showing lesional tissue consisting of epithelium and connective tissue. $(\mathrm{H}$ and $\mathrm{E}, \times 40)$

Fig 6. Parakeratinized stratified squamous epithelium showing pseudoepitheliomatous hyperplasia. ( $\mathrm{H}$ and $\mathrm{E}$, $\times 100)$

Fig 7. Large polygonal neoplastic cells exhibiting mild hyperchromatism and mild pleomorphism $(\mathrm{H}$ and $\mathrm{E}$, $\times 400)$

Fig 8. Hemostasis achieved

Fig 9. After Primary closure

\section{References}

1. Abrikossoff Uber Myome ausgehend von der quergestreiften Willkürlichen muskulatur Virchows Arch Pathol Anat, 260 (1) (1926), pp. 215-233

2. Collins BM, Jones AC. Multiple granular cell tumors of the oral cavity: report of a case and review of the literature. J Oral Maxillofac Surg. 1995; 53:707-11.

3. Wright: Chapter in book: Weiss SW, Goldblum JR. Granular cell tumor In: Enzinger and Weiss's (2001) soft tissue tumors. 4th ed. St Louis, Mo Mosby; 2001. p. 1178-87.

4. Daniels JS. Granular cell tumor of tongue: A case report. Saudi Dent J 2009;21:75-8.

5. Sposto MR, Navarro, CM, de Andrade CR. Granular cell tumor (abrikossof tumor): Case report. Oral Oncol Extra 2006;42:194-7.

6. Vered M, Carpenter WM, Buchner A. Granular cell tumor of the oral cavity: Updated immunohistochemical profile. J Oral Pathol Med. 2009;38:150-9.

7. Chrysomali E, Nikitakis NG, Tosios K, Sauk JJ, Papanicolaou SI. Immunohistochemical evaluation of cell proliferation antigen Ki-67 and apoptosis-related proteins Bcl-2 and caspase-3 in oral granular cell tumor. Oral Surg Oral Med Oral Pathol Oral Radiol Endod 2003;96:566-72.

8. Regezi J.A., Scuibba J. fourth ed. Saunders; Philadelphia, PA: 2003. Oral Pathology: Clinicalpathologic Correlations. pp. 171-173.

9. Leboulanger N, Rouillon I, Papon JF, et al. Childhood granular cell tumors: two case reports. Int J Pediatr Otorhinolaryngol. 2008;72:279-283.

10. Guilliani M., Lajolo C., Pagnoni M., Boari A., Zannonni G.F. Granular cell tumor of the tongue (Abrikossoff's tumor). A case report and review of the literature. Minerva Stomatol. 2004;53:465-469.

\section{Figures}

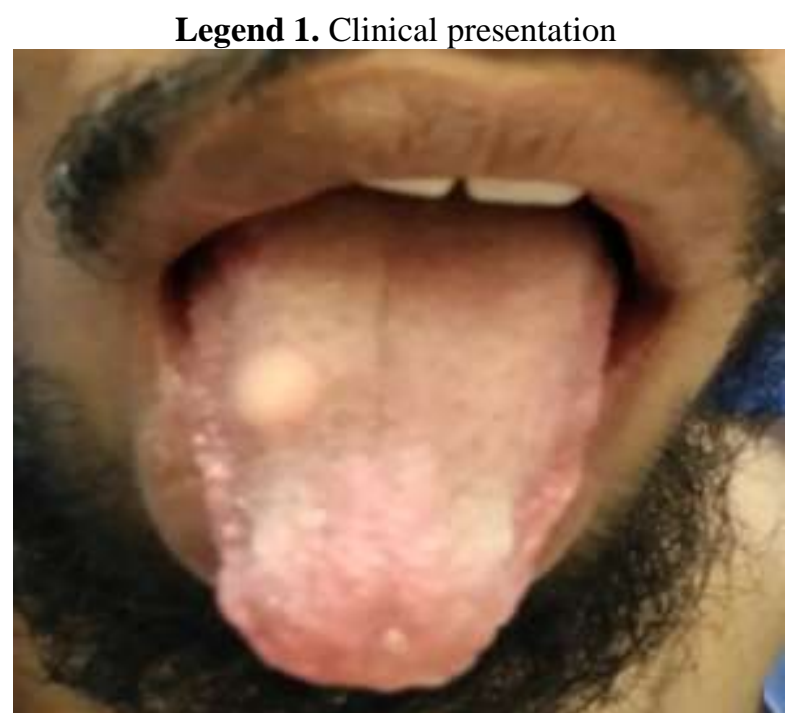

Legend 2.Firm, non pedunculated swelling on dorsum of tongue 


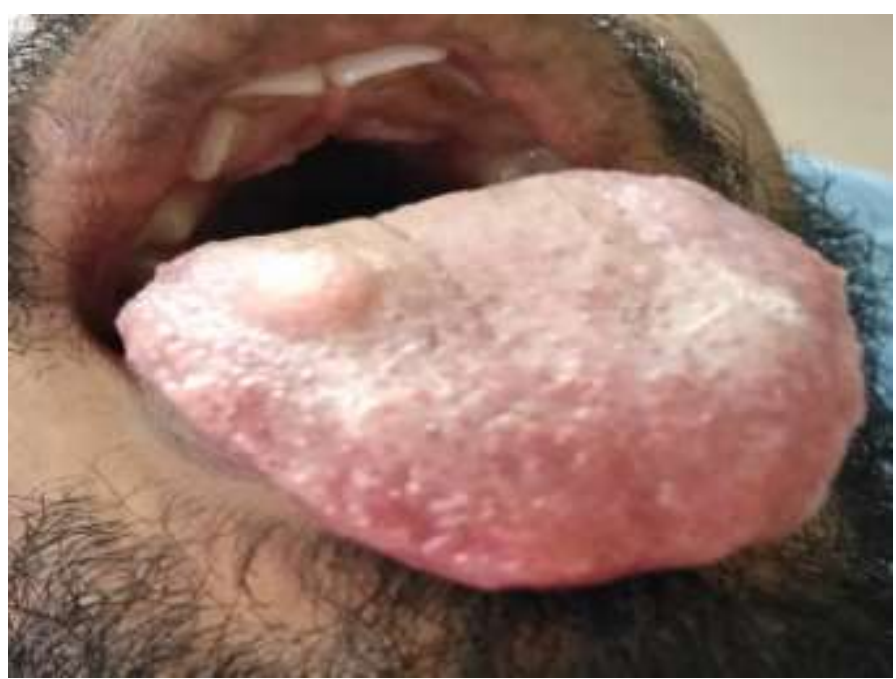

Legend 3.Excision of lesion in to

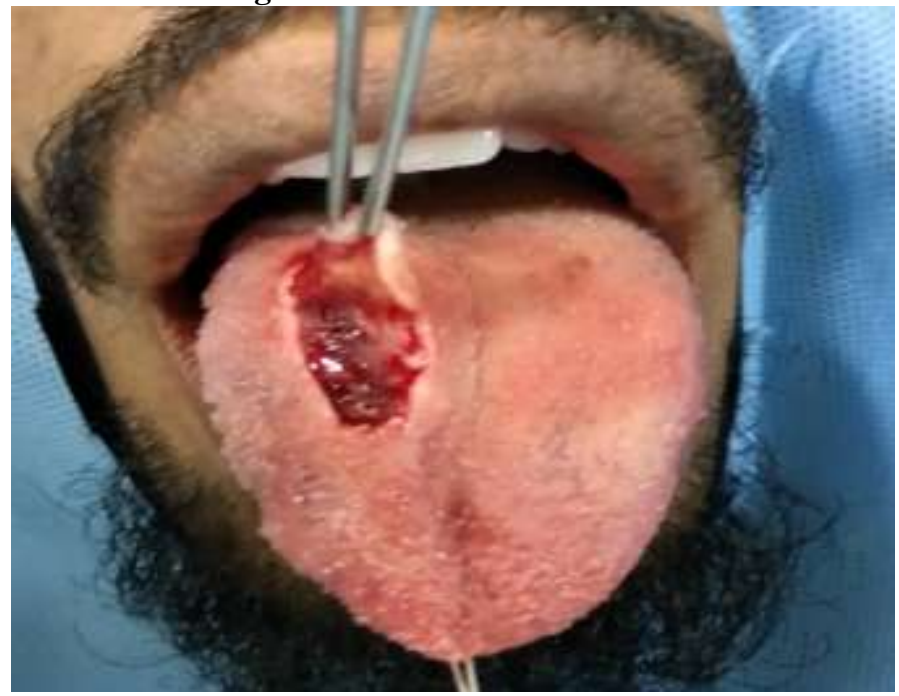

Legend 4.Excised specimen

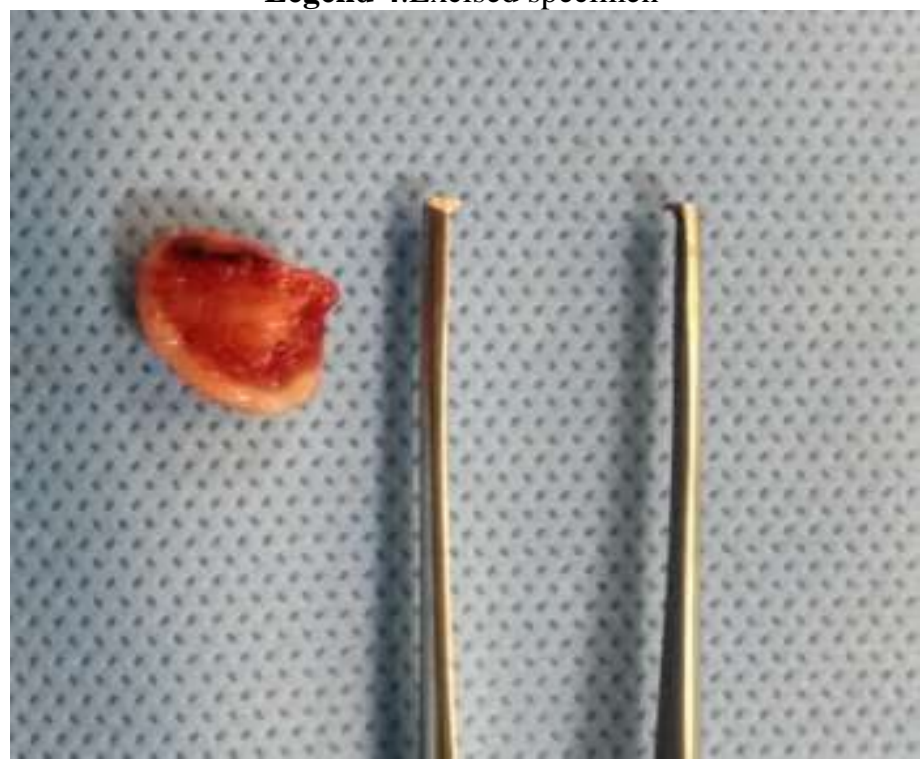


Legend 5. Photomicrograph showing lesional tissue consisting of epithelium and connective tissue. ( $\mathrm{H}$ and $\mathrm{E}$,

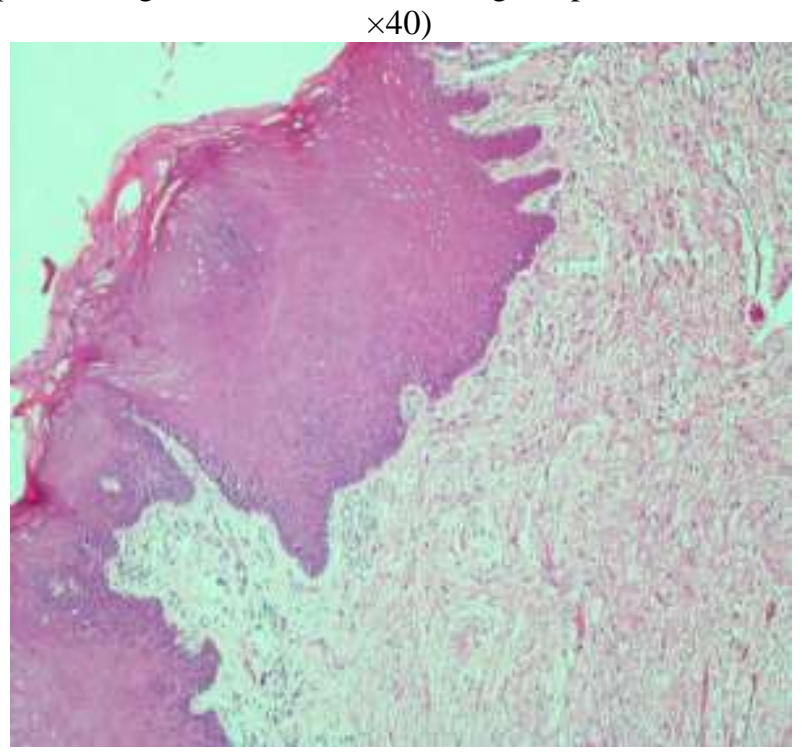

Legend 6.Parakeratinized stratified squamous epithelium showingpseudoepitheliomatous hyperplasia. (H and E, $\times 100)$

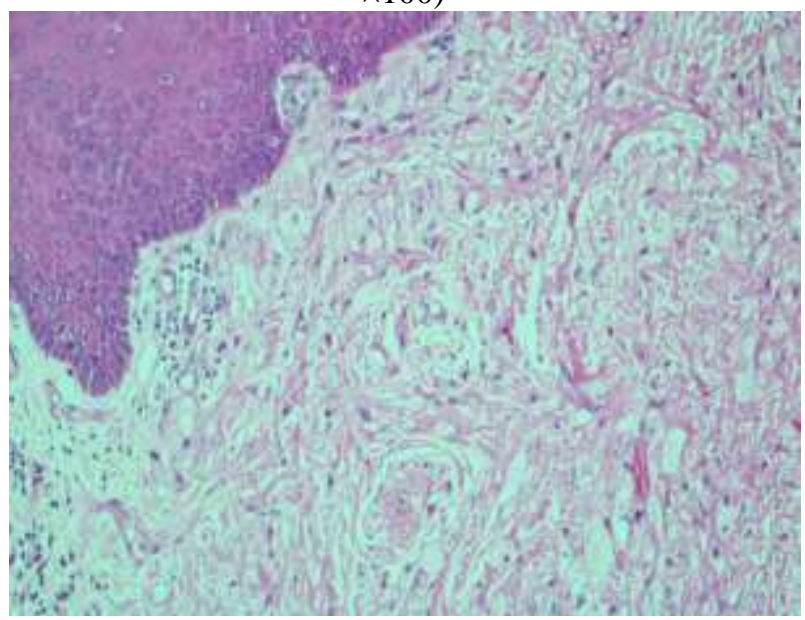

Legend 7.Large polygonal neoplastic cells exhibiting mild hyperchromatism and mild pleomorphism (H and E, $\times 400$ )

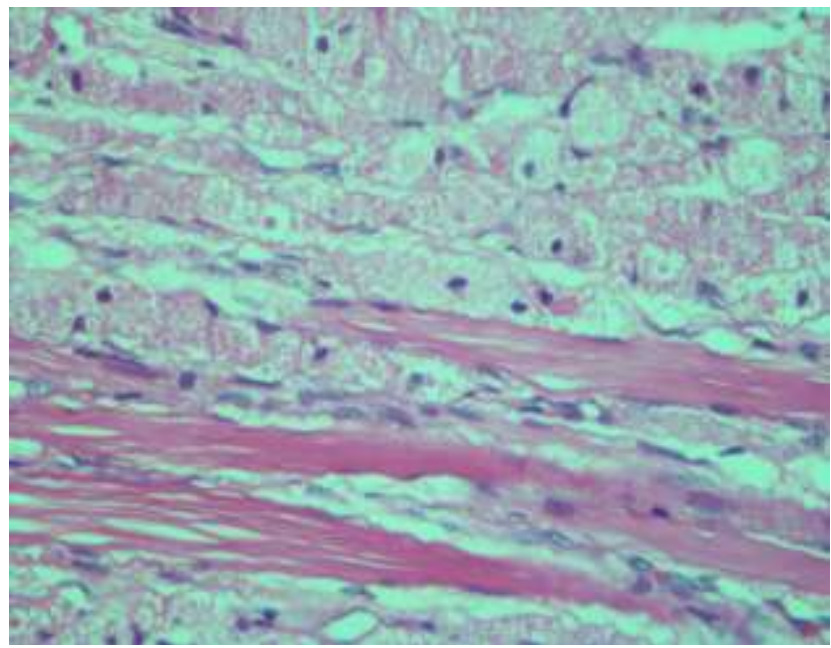




\section{Legend 8.Hemostasis achieved}

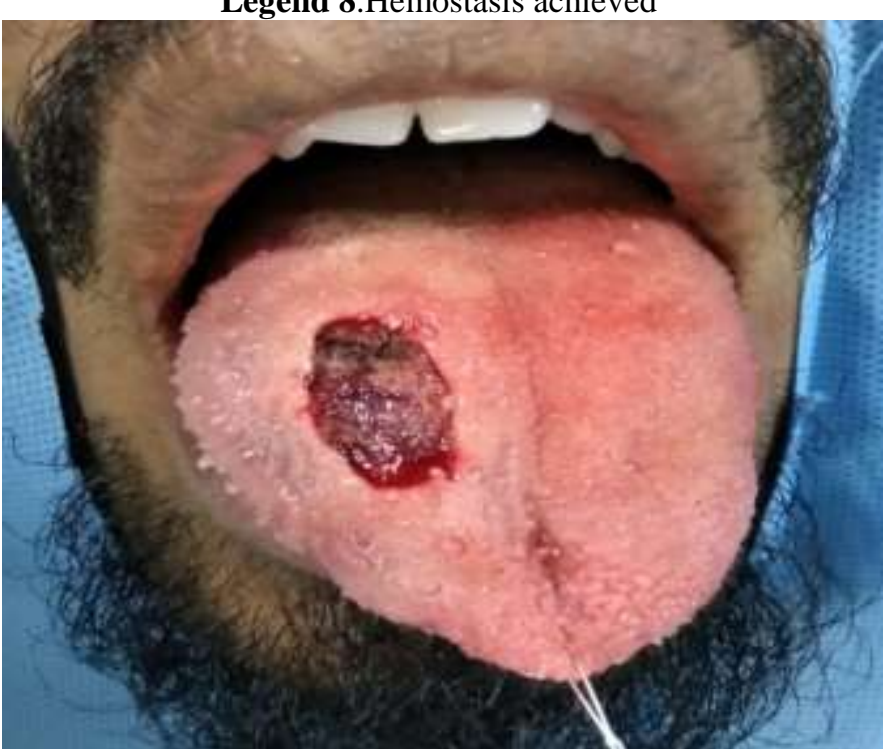

Legend 9.After Primary closure

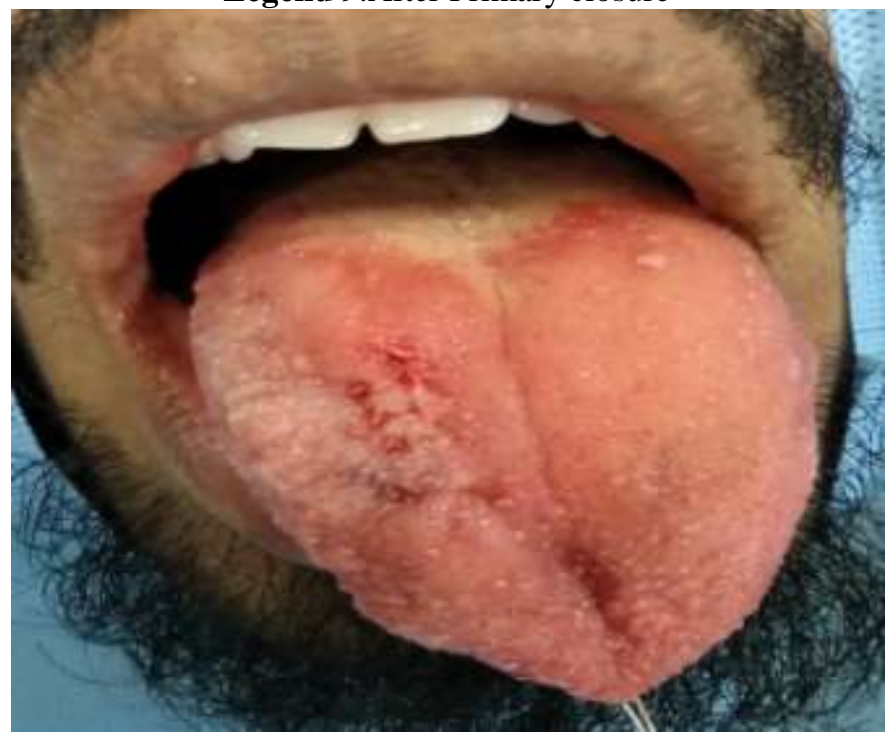

